\title{
Synthesis of seminal ribonuclease in isolated lobules of bull seminal vesicles
}

\author{
N. Quarto, G. F. Tajana* and G. D'Alessio \\ Department of Organic and Biological Chemistry, University of Naples, Via Mezzocannone 16, \\ 80134-Napoli, and "Institute of Histology and General Embryology, University of Reggio Calabria, \\ Catanzaro-88100, Italy
}

\begin{abstract}
Summary. A procedure is described for preparing and maintaining in culture isolated lobules of bovine seminal vesicles, consisting of glandular acini, surrounded by little connective tissue and with free access to the external medium, in which secreted material can be collected. After $48 \mathrm{~h}$ in culture, the isolated lobules appeared indistinguishable, by morphological and biochemical criteria, from freshly isolated lobules. After much longer culture times about one third of the glandular cells were still capable of effective protein synthesis. Studying the biosynthesis of seminal ribonuclease with preparations of isolated lobules we found that: (1) the enzyme was synthesized and secreted; (2) only the fully amidated isoenzyme was synthesized and secreted, indicating that production of the selectively deamidated isoenzymic forms occurred after secretion; (3) newly synthesized protein was rapidly exported, indicating that the high levels of enzyme previously reported for the seminal vesicle tissue were essentially due to its content of stored secretion.
\end{abstract}

\section{Introduction}

Bovine seminal plasma is a rich source of many diverse biochemicals (Mann \& Lutwak-Mann, 1981). Among these is a ribonuclease, BS-RNase, at the very high concentration, for an enzyme in a biological fluid, of 1-2 mg/ml fluid (D'Alessio et al., 1972). It has been demonstrated that BS-RNase (Furia et al., 1983), nerve growth factor (Harper et al., 1982; Korsching et al., 1985), and opioids (unpublished results) are endogenous products of bull seminal vesicles. An understanding of the physiological roles of these proteins and peptides in seminal plasma and/or in seminal vesicles would be of interest because it might shed light on unknown aspects of the seminal vesicle physiology. We have therefore studied the synthesis of BS-RNase, the most abundant of the known products of bull seminal vesicles, in homogeneous preparations of lobules isolated from these glands.

\section{Materials and Methods}

Isolation of seminal vesicle lobules. Bull seminal vesicles, obtained from a local slaughterhouse, were removed from sexually mature animals and immediately introduced, with their main ducts blocked by clamps, into sterile containers. All subsequent procedures were carried out under sterile conditions. After removing the connective sheath, the glandular tissue was minced with scissors into pieces not larger than $5 \mathrm{~mm}$ in diameter. These were left for $2 \mathrm{~h}$ in

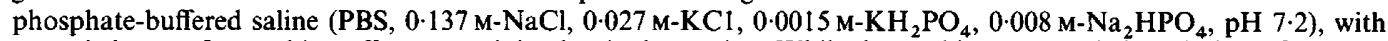
several changes for washing off any remaining luminal secretion. While the washings proceeded, each tissue fragment was dissociated under a dissecting stereomicroscope into smaller fragments, each consisting of few associated acini, surrounded by as little connective tissue as possible.

Labelling with $\int^{35} \mathrm{~S} /$ methionine. Dissected and washed lobules $\left(50-200 \mathrm{mg}\right.$ fresh weight) were incubated at $37^{\circ} \mathrm{C}$ in methionine-free Dulbecco's modified Eagle's medium (DMEM, Gibco, Grand Island, NY, U.S.A.) to which were added $300 \mu \mathrm{Ci}\left[{ }^{35} \mathrm{~S}\right]$ methionine $/ \mathrm{ml}$ (Amersham, Bucks, U.K.; sp. act. $800 \mathrm{Ci} / \mathrm{mmol}$ ). At the end of the labelling period, 
the lobules were separated from the incubation medium by centrifugation at $165 \mathrm{~g}$ for $5 \mathrm{~min}$, and washed twice with cold PBS. The separated media were clarified by centrifugation. Incorporation was determined by counting, in Lumagel (Lumac, Schaesberg, The Netherlands), aliquants of lysed lobules and of incubation media precipitated on glass fibre filters (Gelman, Ann Arbor, MI, U.S.A.) with 10\% trichloracetic acid. Lobules were lysed by hand homogenization in $20 \mathrm{~mm}$-Tris- $\mathrm{HCl}$, pH $7 \cdot 5$, containing $0 \cdot 5 \% \mathrm{SDS}$.

Histological and histochemical methods. Explants were fixed in a formol:methanol $(9: 1, \mathrm{v} / \mathrm{v})$ solution containing $1 \%$ cetylpyridinium chloride at $4^{\circ} \mathrm{C}$ for $12 \mathrm{~h}$. After dehydration in an ethanol series and infiltration with xylol, paraffin-wax sections were cut at 4-6 $\mu \mathrm{m}$ and stained with haematoxylin and eosin, or Mallory's triple stain.

Histochemistry was carried out with the PAS diastase procedure and with Alcian blue $8 \mathrm{gX}$ (Pearse, 1968); with toluidine blue at several $\mathrm{pH}$ values from $2 \cdot 5$ to $7 \cdot 0$; and with PAS and Alcian blue after acid hydrolysis, methylation at $22^{\circ} \mathrm{C}$ and saponification.

Other methods. Purification of RNase from bull seminal vesicles and high-performance ion-exchange chromatography of proteins on a Mono-S column with a Pharmacia apparatus were performed as described by Tamburrini et al. (1986).

Electrophoresis on polyacrylamide gels with sodium dodecyl sulphate (SDS) was carried out as described by Laemmli (1970) and modified by Bonatti \& Descalzi Cancedda (1982), with a monomer concentration of $12 \%$. Detection of labelled protein bands was carried out by fluorography according to Bonner \& Laskey (1974). Immunoblotting of electrophoresed gels was performed following the procedure of Taban et al. (1983) with an antiserum prepared and purified as described by Cantarella et al. (1976). Proteins were determined as described by Bradford (1976) with a commercially available protein assay (Bio-rad, Segrate, Milano, Italy), using bovine serum albumin as a standard.

Affinity chromatography was carried out by the procedure of Wiarenga et al. (1973) with agarose 5-aminophenyl-phosphoryl-uridine-2'(3')-phosphate (Miles-Yeda, Israel) on $0.9 \times 2.4 \mathrm{~cm}$ columns, equilibrated with $20 \mathrm{~mm}$ sodium acetate at $\mathrm{pH} 5 \cdot 2$, washed with the same buffer containing $100 \mathrm{~mm}-\mathrm{NaCl}$ and eluted with $200 \mathrm{~mm}$-acetic acid containing $1 \mathrm{M}-\mathrm{NaCl}$.

\section{Results}

\section{Characterization of isolated lobules}

Morphological observations were carried out on isolated lobules: (i) immediately after their preparation, and (ii) after suitable time intervals in which the lobules were maintained at $37^{\circ} \mathrm{C}$, in an atmosphere of $5 \% \mathrm{CO}_{2}$ in DMEM with $10 \%$ fetal calf serum. Figures 1 (a) and 1 (b) show that the glandular epithelium of the lobules maintained for $48 \mathrm{~h}$ in culture, was virtually indistinguishable from that of freshly isolated lobules. Cells, columnar in shape, with a basophilic cytoplasm and PAS-positive, were organized in compact palisades, while the surrounding connective tissue appeared rather swollen.

After $72 \mathrm{~h}$ in culture (see Fig. Ic), signs of loss of structure were detected in the epithelium, where the palisades appeared less ordered, because of an incipient involution of the basal membrane. At this stage, cells appeared to be less cylindrical, with less PAS staining, while swelling and disorganization of the connective tissue had increased. Lobules kept for 7 days in culture showed clear signs of decay (see Fig. 1d). However, significant portions of the epithelium still showed a palisade structure, made up of columnar, PAS-positive, polarized cells (see Fig. 2).

At each of the times indicated above, samples of lobules were washed and incubated with $\left[{ }^{35} \mathrm{~S}\right]$ methionine for $24 \mathrm{~h}$. At the end of the incubation time, the lobules were separated from their media by centrifugation, washed twice with cold PBS, lysed, and analysed by polyacrylamide gel electrophoresis in SDS. Samples from the incubation media, clarified by centrifugation were also analysed. Equal amounts of radioactivity were loaded onto the gels, for the samples prepared from lobules and those of the corresponding incubation media.

Figure 3 shows that the patterns of newly synthesized proteins obtained from lobules maintained in culture for 24,48 and $72 \mathrm{~h}$ and also that from lobules kept for 7 days were not greatly different from each other, although an increase with time of bands of lower molecular size was detected, presumably due to an increased proteolysis. Also, the pattern of the proteins found in the media did not change detectably with prolonged culture time (see Fig 3.).

Incorporation of $\left[{ }^{35}\right.$ S $]$ methionine in lobules maintained in culture for up to $48 \mathrm{~h}$ did not decrease significantly with respect to the value $\left(3 \times 10^{8}\right.$ d.p.m. $/ \mathrm{mg}$ protein $)$ found for lobules 


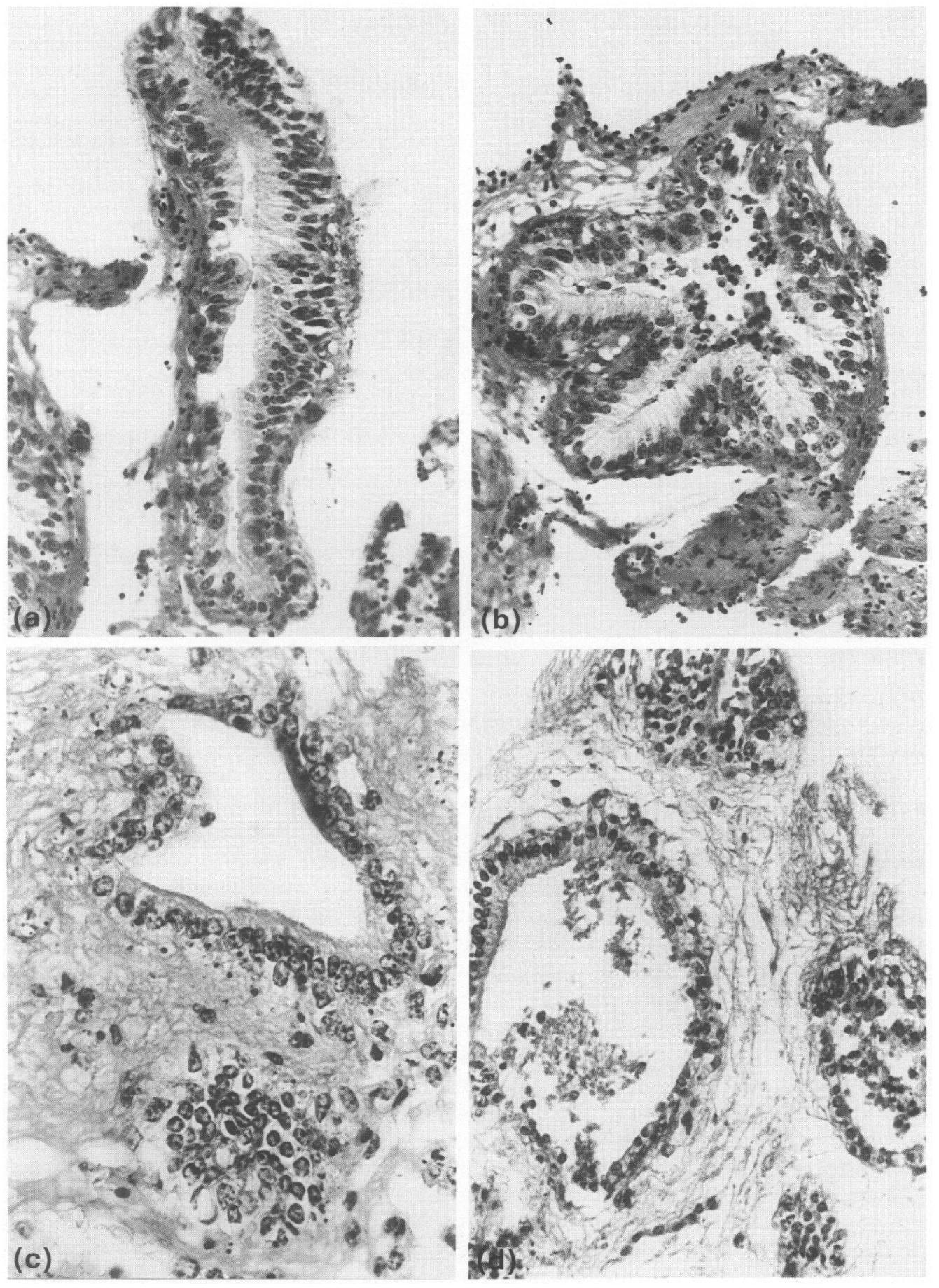

Fig. 1. Isolated lobules from bovine seminal vesicles maintained in culture for: 0 (a), 48 (b) and 72 (c) hours, and 7 days (d). The epithelial cells do not show significant alterations up to $48 \mathrm{~h}$; after $72 \mathrm{~h}$ most epithelial cells still appear to keep their typical morphology and organization, whereas after 7 days in culture, the glandular epithelium shows little organization. $\times 270$. 


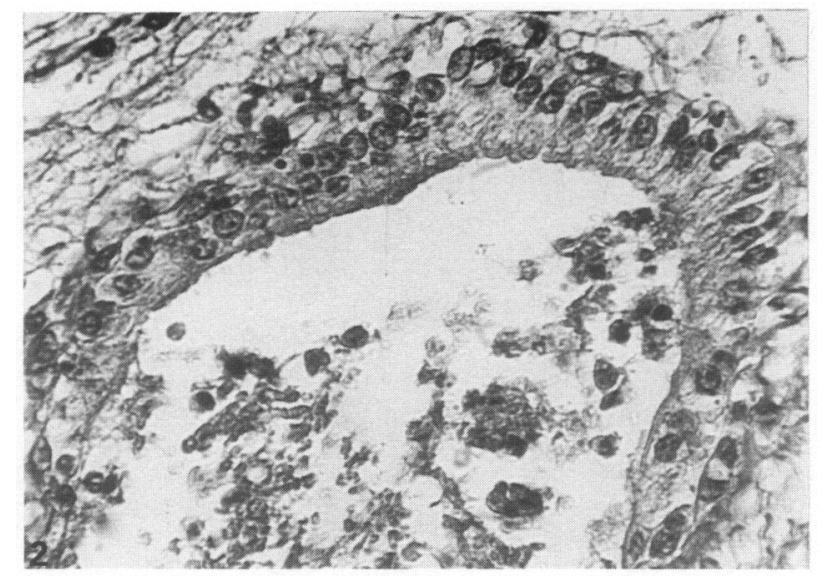

Fig. 2. A detail of an isolated lobule from bovine seminal vesicles maintained in culture for 7 days showing remnants of cells columnar in shape and organized in a palisade structure. $\times 290$.

labelled immediately after isolation. After $72 \mathrm{~h}$ of culture, incorporation dropped to about $30 \%$ of the value obtained at zero time, while the value of 7 days was still of the same order.

\section{Characterization of BS-RNase synthesized by isolated lobules}

BS-R Nase was purified from lobules washed of their secretion liquid for several hours and then labelled for a short $(3 \mathrm{~h})$ or a long $(18 \mathrm{~h})$ labelling time with $\left[{ }^{35} \mathrm{~S}\right]$ methionine. A new purification protocol had to be defined, as the extraction with dilute sulphuric acid indicated by previous methods (D'Alessio et al., 1972; Tamburrini et al., 1986) increased the rate of radiolysis of the labelled precursor.

The new method, which gave yields of RNase comparable to those of the previous methods, consisted of an extraction step with $0.5 \mathrm{M}$-acetic acid, followed by fractionation of the acid extract with ammonium sulphate. Proteins precipitated between 50 and $100 \%$ saturation of ammonium sulphate were collected by centrifugation and dialysed against $\mathrm{H}_{2} \mathrm{O}$ containing $1 \mathrm{mg}$ purified BS-RNase/ml, added both as a carrier and as an internal standard. After an affinity chromatography step, final purification and separation of subforms was achieved by cation exchange chromatography on a Mono-S column.

Purification of the enzyme from the culture media, equilibrated with $0.5 \mathrm{M}$-acetic acid by dialysis, was carried out with the same protocol. All purification steps were done at $4^{\circ} \mathrm{C}$. The results are given in Table 1 .

For the affinity chromatography step the figures reported in Table 1 are those calculated for the material coeluting with the BS-RNase added as an internal standard. Besides the radioactivity passing unretarded through the affinity gel, and the peak of radioactivity corresponding to BS-RNase, eluted by $200 \mathrm{~mm}$-acetic acid containing $1 \mathrm{M}-\mathrm{NaCl}$, a radioactive peak was eluted by $20 \mathrm{~mm}$-sodium acetate at $\mathrm{pH} 5 \cdot 2$, containing $100 \mathrm{~mm}-\mathrm{NaCl}$ (see Fig. 4). This radioactivity peak, in some cases more conspicuous than the RNase peak, was detected in all purification experiments carried out on lobules as well as on their culture media, with $3 \mathrm{~h}$ and with $18 \mathrm{~h}$ labelling times.

When this material was rechromatographed on the affinity column, it eluted at the same elution volume, excluding the possibility that its presence was due to overloading of the affinity column. Upon electrophoresis on polyacrylamide gels in SDS, in the presence of a reducing agent, the labelled material was resolved into several bands (data not shown). The major band, comigrating 
with that of the BS-RNase subunit, was recognized by antibodies to BS-RNase on an immuno-blot of the electrophoresed gel. These results indicate that the labelled material eluted at $\mathrm{pH} 5 \cdot 2$ from the affinity column contains BS-RNase subunits, and therefore presumably consists of the BS-2 component(s) of BS-RNase made up of BS-RNase subunits linked by interchain disulphides to other protein moieties (D'Alessio et al., 1981).

The material coeluting with standard BS-RNase on the affinity column was chromatographed on a Mono-S cation exchange column, which resolved BS-RNase into its three isoenzymic forms $\alpha_{2}, \alpha \beta$ and $\beta_{2}$ (see Fig. 5). The elution of radioactive material after one column volume (see Fig. 5) was not due to overloading effects, because this material did not adsorb on the column after rechromatography. In fact, the material was found to contain less than $10 \%$ protein after TCA precipitation and SDS gel electrophoresis (data not shown).

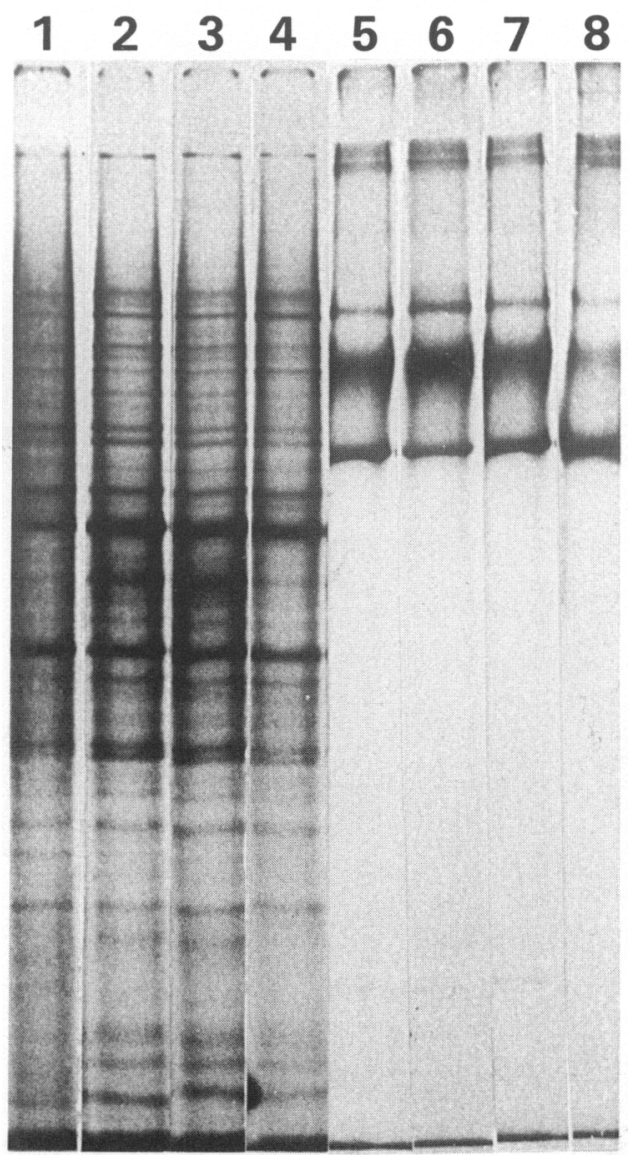

\section{Lobules}

Media

Fig. 3. Fluorography of electrophoretic patterns on polyacrylamide gels in SDS of lysed lobules labelled with ${ }^{35}$ S]methionine and of their respective media: samples and lane numbers (in

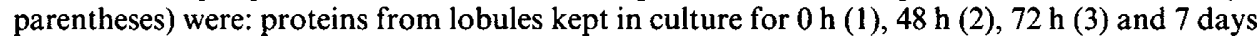
(4); proteins from the incubation media of 0 -h (5), 48-h (6), 72-h (7) and 7-day (8) lobule preparations. 
Table 1. Purification of ${ }^{35} \mathrm{~S}$-labelled BS-RNase from isolated seminal vesicle lobules in culture and their respective culture media

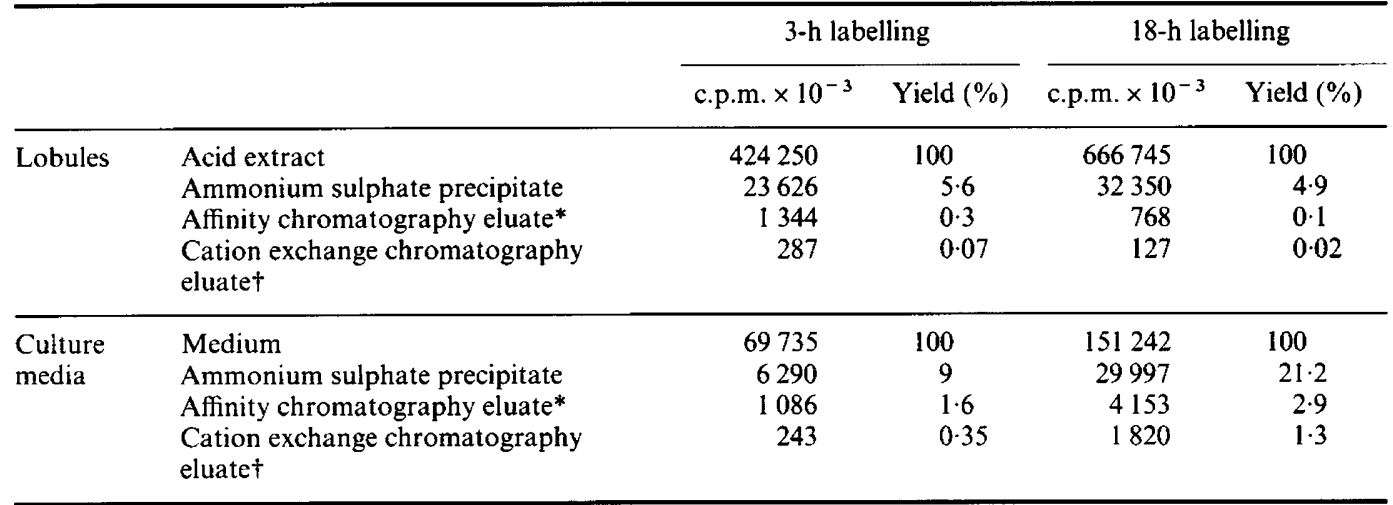

The values are averages from 2 independent experiments carried out on lobules isolated from seminal vesicles removed from different animals. The values differed by 5-16\%. Incorporation values, obtained with $100-200 \mathrm{mg}$ lobules (fresh weight), were normalized to I $\mathrm{g}$ of lobules.

* Radioactive material coeluting with the BS-RNase carrier.

†The sums of the values obtained for the three enzyme forms (see Fig. 5).

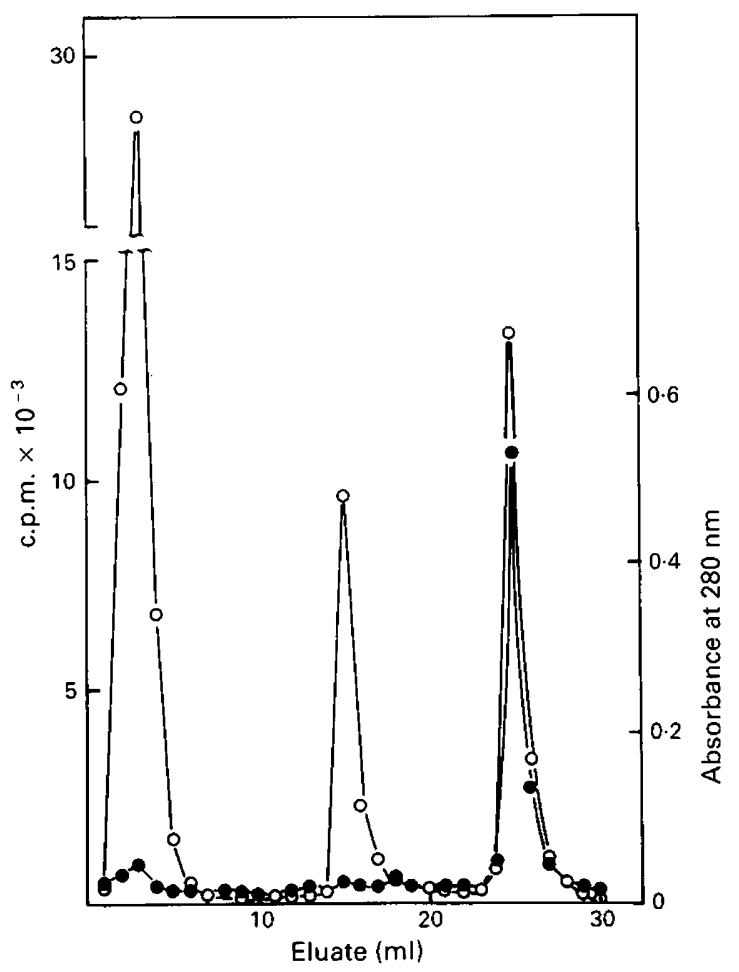

Fig. 4. Affinity chromatography on agarose linked 5-amino-phenyl-phosphoryl-uridine- $2^{\prime}\left(3^{\prime}\right)$ phosphate of proteins precipitated with ammonium sulphate from an extract of seminal vesicle lobules incubated with $\left[{ }^{35}\right.$ S]methionine. The sample was added with an aliquant of pure BS-RNase. The column, equilibrated with $20 \mathrm{~mm}$-sodium acetate at $\mathrm{pH} 5 \cdot 2$, was washed with the same buffer containing $100 \mathrm{~mm}-\mathrm{NaCl}$ and eluted with $200 \mathrm{~mm}$-acetic acid containing $1 \mathrm{M}-\mathrm{NaCl}$. 


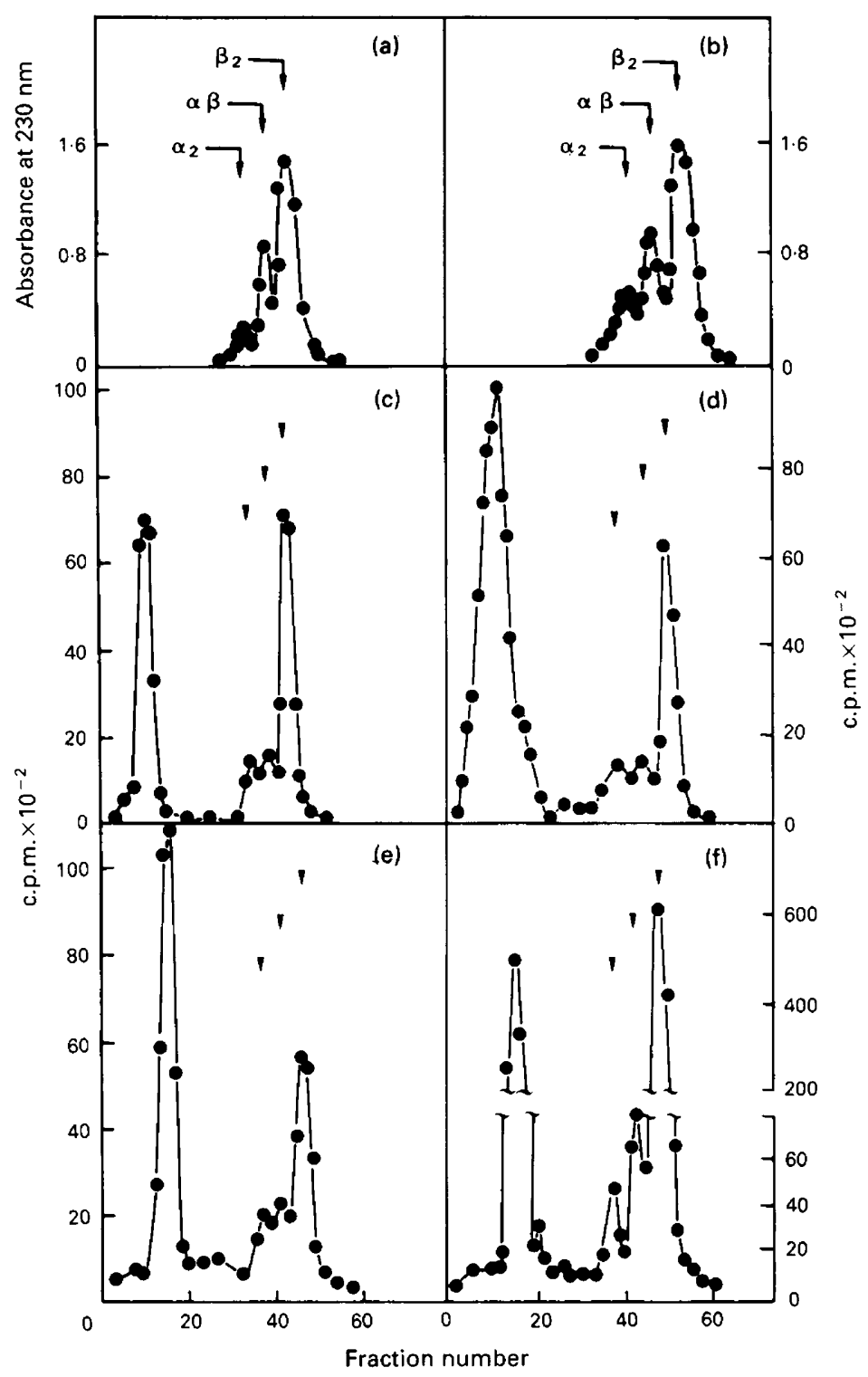

Fig. 5. Cation exchange chromatography on a Mono $\mathrm{S}$ column of newly synthesized BS-RNase prepared: from seminal vesicle lobules labelled for $3 \mathrm{~h}(\mathrm{c})$ and $18 \mathrm{~h}(\mathrm{~d})$ with $\left[{ }^{35}\right.$ S]methionine and from their respective incubation media ( $e$ and $f$ ). Arrowheads indicate the elution volumes of BS-RNase isoenzymic forms $\alpha_{2}, \alpha \beta$ and $\beta_{2}$. Typical patterns of BS-RNase purified from bovine seminal vesicle tissue (a) and from seminal plasma (b) are also shown.

The figures reported in Table 1 for the BS-RNase eluted from the Mono-S cation exchange column were calculated by summing the individual figures obtained for the three enzyme subforms, which were resolved by the Mono-S column. Taking into consideration the relative ratios of the three subforms, we found (see Fig. 5) that in the newly synthesized BS-RNAase the proportion of fully amidated $\beta_{2}$ isoenzyme was much higher than that reported for the enzyme purified from seminal plasma or from seminal vesicles (Di Donato \& D'Alessio, 1981; Tamburrini et al., 1986). 
Slightly higher proportions of $\alpha_{2}$ and $\alpha \beta$ subforms were found in the newly synthesized enzyme as isolated from the culture medium (see Fig. 5). However, these values are still much lower than those reported for the enzyme isolated from seminal plasma.

\section{Discussion}

The physiological role of seminal vesicles is considered to be the production and storage of seminal plasma, until ejaculation occurs. The fraction of seminal plasma contributed by seminal vesicles appears to vary with species, and is particularly relevant in the human and the bovine species (Spring-Mills, 1980; Mann \& Lutwak-Mann, 1981). In bovine seminal plasma, a great number of substances, as diverse as sugars, nitrogenous bases, enzymes and biopeptides, have been found, some of them being present at high concentrations (Mann \& Lutwak-Mann, 1981). The possibility that such substances are synthesized in different organs and delivered to the seminal vesicles can be discarded since it has been demonstrated that the genes responsible for the synthesis of some of these molecules are actively expressed in seminal vesicle tissue (see 'Introduction').

These findings provoke the question of the physiological meaning of the production and storage in seminal vesicles of these molecules, as well as of their presence in seminal plasma. Besides the possibility that the gland produces them in its exocrine capability, it may be considered that they are produced as hormones acting in a paracrine or an autocrine fashion. Recently, it has been found that $\beta$-endorphin is synthesized in the testis by the Leydig cells (Pintar et al., 1984) and interacts with receptors on the Sertoli cells (Fabbri et al., 1985).

An experimental approach to this question is that of studying the biosynthesis of these molecules, and its regulation, in glandular structures of seminal vesicles isolated from the other components, stromal and muscular, as well as from external stimuli, delivered through the blood or the nerve paths.

We were unable to develop for bovine seminal vesicles an in-vitro cell system, such as those used for rat seminal vesicles (Higgins et al., 1981; Kierszenbaum et al., 1983; Tajana et al., 1984), even after repeated trials, and with different conditions. The possibility was considered of the existence in bovine seminal vesicles of a factor inhibiting cell attachment, as we observed that no cells from the explants, not even fibroblasts, attached to the plates.

The procedure adopted for the present study provided preparations of isolated lobules, which can be kept in culture for at least $48 \mathrm{~h}$ with no apparent damage, morphological or biochemical, to the glandular epithelium. The system can be considered a prototype, which may be optimized according to the special needs of the biochemical problem under study. It has the advantages, with respect to a primary cell culture, that the polarity of the gland cells is preserved and that relatively conspicuous amounts of tissue can be handled. Furthermore, the tissue basic architecture is also preserved and yet the gland cells have free access to the medium, hence can be effectively tested with hormones and factors, to assess any controls on the biosynthetic processes. Use of such procedures for studying the biosynthesis of BS-RNase showed that the isolated lobules are able to synthesize and export the protein and that the culture medium can be considered as a secretion reservoir.

Relatively low amounts of BS-RNase were found in the gland tissue and in the external medium after $3 \mathrm{~h}$ of incorporation. However, with a longer incorporation time, the enzyme in the secretion medium represented about $1 \cdot 3 \%$ of the total secreted proteins, a value comparable to that of the ejaculated seminal plasma. These results indicate: (i) that the high levels of enzyme reported for the seminal vesicle tissue (Tamburrini et al., 1986) can in fact be attributed to the tissue secretion stored in the gland, rather than to the cell tissue itself; (ii) that once synthesized, BS-RNase is rapidly released into the luminal secretion.

Another observation of interest on the biosynthesis of BS-RNase concerns the isoenzymic pattern of the newly synthesized protein, as extracted from the lobules or secreted into the medium. In either case, we found only small amounts of $\alpha_{2}$ and $\alpha \beta$ isoenzymes, i.e. of isoenzymes containing 
the selectively deamidated $\alpha$ subunit (Di Donato \& D'Alessio, 1981). Even the small amounts we detected were perhaps artefactually produced through deamidation occurring during the purification of the enzyme. This suggests that selective deamidation of BS-RNase, and the subsequent production of methyl-accepting iso-aspartyl residues (Di Donato et al., 1986), occurs only after the protein has been exported from the cells into the secretion medium.

This work was partly financed with grants from the Consiglio Nazionale delle Ricerche and from the Ministry of Public Education, Italy.

\section{References}

Bonatti, S. \& Descalzi-Cancedda, F. (1982) Posttranslational modification of Sindbis virus: electrophoretic analysis of pulse-chase labelled infected cells. J. Virol. 42, 64-70.

Bonner, W.M. \& Laskey, R.A. (1974) A film detection method for tritium labelled proteins and nucleic acids in polyacrylamide gels. Eur. J. Biochem. 46, 83-88.

Bradford, M.M. (1976) A rapid and sensitive method for the quantitation of microgram quantities of protein utilizing the principle of protein-dye binding. Analyt. Biochem. 72, 248-254.

Cantarella, M., Lamberti, C., Cacciapuoti G., De Prisco, R., Malorni M.C. \& D'Alessio, G. (1976) Isolamento mediante cromatografia di affinità di anticorpi diretti verso $i$ determinanti antigenici comuni e specifici di RNAasi BS-1 ed RNAasi A. Boll. Soc. It. Biol. Sper. 52, 204-210, 1976.

D'Alessio, G., Floridi, A., De Prisco, R., Pignero, A. \& Leone E. (1972) Bull seminal ribonucleases. I. Purification and physicochemical properties of the major component. Eur. J. Biochem. 26, 162-167.

D'Alessio, G., Di Donato, A., Furia, A., Leone, E., Libonati, M., Parente, A. \& Suzuki, H. (1981) Bull Semen RNAase revisited. J. molec. Biol. 146, 269-274.

Di Donato, A. \& D'Alessio, G. (1981) Heterogeneity of bovine seminal ribonuclease. Biochemistry, N.Y. 20 , $7232-7237$.

Fabbri, A., Tsai Morris, C.H., Luna, S., Fraioli, F. \& Dufan, M. (1985) Opiate receptors are present in the rat testis. Identification and localization in Sertoli cells. Endocrinology 117, 2544-2546.

Furia, A., Palmieri M. \& Libonati, M. (1983) Bovine seminal ribonuclease precursor synthesis in vitro. Biochim. Biophys. Acta 741, 303-307.

Harper, G.P., Glanville, R.W. \& Thoenen, H. (1982) The purification of nerve growth factor from bovine seminal plasma. J. biol. Chem. 257, 8541-8548.

Higgins, S.J., Brooks, D.E. \& Fuller, F.M. (1981) Isolation of cells from rat seminal vesicles and epididymis and their use in studying androgen action. Molec. cell. Endocrin. 23, 207-223.
Kierszenbaum, A.L., DePhilip, R.M., Spruill, A.W. \& Takenaka, I. (1983) Isolation and culture of rat seminal vesicle epithelial cells. Expl Cell Res. 145, 293-304.

Korsching, S., Auburger, G., Heumann, R., Durgerian, S. \& Thoenen, H. (1985) Levels of nerve growth factor and its mRNA in the central nervous system of the rat correlate with cholinergic innervation. EMBO J. 4, 1389-1393.

Laemmli, U.K. (1970) Cleavage of structural proteins during the assembly of the head of bacteriophage T4. Nature, Lond. 227, 680-685.

Mann, T. \& Lutwak-Mann, C. (1981) Male Reproductive Function and Semen. Springer-Verlag, Berlin.

Pearse, A.G.E. (1968) Histochemistry: Theoretical and Applied, vol. 1, p. 294, Churchill Ltd, London.

Pintar, J.E., Schacter, B.S., Herman, A.B., Durgerian, S. \& Krieger, D.T. (1984) Characterization and localization of proopiomelanocortin messenger RNA in the adult rat testis. Science, N.Y. 225, 632-634.

Spring-Mills, E. (1980) The seminal vesicles. In Male Accessory Sex Glands, pp. 63-77. Eds E. SpringMills \& E. S. E. Hafez. Elsevier-North Holland, Amsterdam.

Taban, J.C., Homsted, J.B. \& Goldman, R.D. (1983) A rapid procedure for preparing fluorescein-labelled specific antibodies from whole antiserum: its use in analyzing cytoskeleton architecture. J. Cell Biol. 97, $1277-1282$.

Tajana, G.F., Locuratolo, P., Metafora, S., Abrescia, P. \& Guardiola, J. (1984) Synthesis of a testosteronedependant secretory protein by rat seminal vesiclederived cell lines. EMBO J. 3, 637-644.

Tamburrini, M., Piccoli, R., De Prisco, R., Di Donato, A. \& D'Alessio, G. (1986) Fast and high yielding procedures for the isolation of bovine seminal RNAase. Ital. J. Biochem. 35, 22-32.

Wiarenga, R.K., Huizinga, J.D., Gaastra, W., Welling, G.W. \& Beintema, J.J. (1973) Affinity chromatography of porcine pancreatic ribonuclease and reinvestigation of the $\mathrm{N}$-terminal amino acid sequence. FEBS Lett. 31, 181-185. 